\title{
TAXONOMIC STATUS OF FACULTATIVE AND STRICTLY ANAEROBIC "CORRODING BACILLI" THAT HAVE BEEN CLASSIFIED AS BACTEROIDES CORRODENS
}

\author{
F. L. Jackson, Yvonne E. Goodman, F. R. Bel, \\ Pui Ching Wong aNd R. L. S. Whitehouse \\ Department of Medical Bacteriology, Faculty of Medicine, University of Alberta, \\ Edmonton, Alberta, Canada
}

\section{Plate XII}

"CORRODING BACILLI" have been reported in the literature during the past 20 yr (Holm, 1950; Eiken, 1958; Reinhold, 1966; Khairat, 1967; Henriksen, 1969). The name Bacteroides corrodens was applied to certain agar-pitting Gram-negative organisms by Eiken. Khairat, investigating strains identified as $B$. corrodens, found that the organisms were strict anaerobes, but other authors have noted the occurrence of morphologically similar facultatively anaerobic ("facultative") organisms. Most available strains conforming to Eiken's description in biochemical and morphological characteristics are facultative, and form a group of biochemically and antigenically related organisms (Henriksen; Jackson, Goodman and Wong, 1969; Jackson et al., 1970a). Identification schemes that include descriptions of anaerobic $B$. corrodens have been published by Dowell and Hawkins (1968).

In the present study, we have attempted to assess the taxonomic status of facultative organisms resembling Henriksen's type strain, no. NCTC10596, and of certain anaerobic organisms that have been classified as $B$. corrodens.

\section{MATERIALS AND METHODS}

Organisms

Facultative strains isolated in Alberta. Seventy-two strains of oxidase-positive, catalasenegative, corroding bacilli were isolated on blood agar plates that had been inoculated with specimens from the University of Alberta Hospital. The sources and numbers of specimens were: sputum, 23; bronchial and tracheal secretions, 8; abdominal wounds, 8; mouth and throat, 7 ; abdominal cavity, 4; finger infections, 4; hand infections (not fingers), 3; ear infections, 3 ; chest drainage, 3 ; neck and submandibular abscesses, 2 ; leg wounds, 2; lung (post mortem), 1; fractured mandible (curetting), 1; antral lavage, 1; eye swab, 1; perineal sinus, 1. Cultures were usually mixed. In four cases (neck abscess, osteomyelitis of finger, post-mortem lung, and antral lavage), facultative corroding bacilli were the only organisms isolated, and Gram-negative bacilli were the only bacteria seen in direct smears. In a submandibular abscess, the corroding bacilli were associated with Actinomyces israelii. In 30 cases, first isolation was on anaerobic plates, but all strains grew aerobically on first subculture. Twenty of these strains were lyophilised and have been included in most tests. When fewer or more strains were tested, this is stated in the text. 
Other strains. Two strains of facultative B. corrodens, no. NCTC10596 (Henriksen's type strain no. 333/54-55) and no. A40/68, and Bacteroides fragilis no. NCTC9343 were from the National Collection of Type Cultures (NCTC), Colindale, London. Another strain of $B$. fragilis and a strain of Bacteroides oralis were provided by Miss Eleanor Bergen, University of Alberta. Strain no. A124/68, isolated from a liver abscess at the Royal Jubilee Hospital, Victoria, British Columbia, was provided by Mrs Anne Johnston.

An organism provisionally identified as anaerobic B. corrodens (no. EDMH1) was isolated from amniotic fluid at the Misericordia Hospital, Edmonton, Alberta. Two closely similar anaerobes, no. UAH1 (infected face lesion) and no. UAH2 (infected heel), were isolated at the University of Alberta Hospital. Dr S. M. Finegold, Veterans' Administration Center, Los Angeles, California, kindly provided an anaerobic, no. B912, and a facultative strain, no. B916. Included in some tests were: Haemophilus aphrophilus no. NCTC5886; Haemophilus canis no. NCTC1659; a recently isolated strain of Haemophilus influenzae; two strains of Vibrio sputorum, no. JV5 and ER33, kindly provided by Dr W. J. Loesche, School of Dentistry, University of Michigan; Vibrio bubulus, no. NCTC10355, and Vibrio fetus, no. NCTC5830.

\section{Morphology and staining}

Microscopy. Smears were fixed for $1 \mathrm{~min}$. with methanol before staining with methylene blue or Gram's stain. Wet preparations were examined by phase-contrast microscopy.

Motility. Three methods were used: (a) hanging drop; $(b)$ wet preparation under coverslip; (c) a thin layer of nutrient agar was placed in a well slide, was inoculated peripherally, and a drop of nutrient broth was added; a coverslip was then applied and sealed with vaseline. For anaerobes, all operations before sealing were performed in a glove-box gassed with 90 per cent. oxygen-free $\mathrm{N}_{2}+10$ per cent. $\mathrm{CO}_{2}$. Preparations incubated at $25^{\circ} \mathrm{C}, 30^{\circ} \mathrm{C}$ and $37^{\circ} \mathrm{C}$ were examined by medium- and high-power phase-contrast at $4 \mathrm{hr}$ and at intervals thereafter for 3 days. By method $(c)$, the few motile forms in cultures of $V$. sputorum were easily detected.

Electron microscopy. Organisms from culture plates were suspended in 2 per cent. phosphotungstic acid that had been adjusted to $p \mathrm{H} \mathrm{7.0} \mathrm{with} \mathrm{N-KOH.} \mathrm{A} \mathrm{drop} \mathrm{of} \mathrm{the} \mathrm{suspen-}$ sion was transferred to a carbon-coated Formvar grid by means of a Pasteur pipette, and excess fluid was removed by touching with the edge of a filter paper. After air drying, the preparations were examined with a Philips 200 or Siemens Elmiskop 1A electron microscope.

\section{Cultural and biochemical methods}

Media. The basal medium, 2.5 per cent. (w/v) Oxoid Nutrient Broth no. 2 with 1.5 per cent. (w/v) Difco Bacto-agar in distilled water, was sterilised by autoclaving for $15 \mathrm{~min}$. at $121^{\circ} \mathrm{C}$. Additions were made as indicated below; $20 \mathrm{ml}$ of medium was poured into each $10 \mathrm{~cm}$ plastic petri dish.

Cystine medium (found by F. R. Bel to give improved growth of the facultative strains) was basal medium with cystine 0.005 per cent. (w/v); for cystine-haemin medium (cystinehaemin-nutrient agar, CHA), recrystallised haemin (Eastman Organic Chemicals) was added to give a final concentration of $25 \mu \mathrm{g}$ per ml. Haemin concentration was varied as indicated in the text. Blood agar was basal medium with 5 per cent. (v/v) defibrinated sheep blood.

Stock solution of haemin. Haemin was dissolved in 0.5 per cent. aqueous $\mathrm{Na}_{2} \mathrm{CO}_{3} \cdot \mathrm{H}_{2} \mathrm{O}$, to a concentration of $5000 \mu \mathrm{g}$ per ml, and sterilised by Millipore filtration. Flu-strips (Case Laboratories, Inc., Chicago) were used for screening strains for haemin requirements.

Fermentation of carbohydrates. Baltimore Biological Laboratories (BBL) Taxo disks were placed on BBL phenol red medium, with added haemin to $25 \mu \mathrm{g}$ per ml. One set of tests was incubated anaerobically without $\mathrm{CO}_{2}$, and another aerobically without $\mathrm{CO}_{2}$. Some tests were by stab inoculation of $10-\mathrm{cm}$ deeps of phenol red medium containing $\mathbf{0} 2$ per cent. agar and 1 per cent. substrate. The term "non-fermentative" indicates failure to produce acid or gas in all these tests. 
Gas-phase conditions. Four main gas-phase conditions were used: (a) air; (b) air with 5 per cent. $\mathrm{CO}_{2} ;(c)$ anaerobic conditions in Baird and Tatlock cold-catalyst jars gassed with hydrogen +10 per cent. $\mathrm{CO}_{2} ;(d)$ anaerobic conditions in jars gassed with hydrogen without $\mathrm{CO}_{2}$. Air- $\mathrm{CO}_{2}$ mixtures were adjusted by means of National Flow-meters and fed into standard glass and stainless-steel desiccator cabinets modified by the addition of two taps. Other mixtures used are specified in the text.

Antibiotic-sensitivity tests. Plate-dilution method: plates were inoculated with a Ridgeway-Watt multipoint inoculator (Ridgeway-Watt, Epsom, England). Inoculum size was standardised by initial adjustment of suspensions of freshly harvested organisms, from $48 \mathrm{hr}$ CHA medium, to absorbance 0.5 (wavelength: $600 \mathrm{~nm}$ ). From this a $10^{-2}$ dilution in 1 per cent. peptone water was prepared as inoculum. Results were read at $48 \mathrm{hr}$.

Catalase test. A few colonies of bacteria were removed from CHA plates with a wire (tested for inertness) and immersed in 3 per cent. $\mathrm{H}_{2} \mathrm{O}_{2}$ in a small tube.

Oxidase test. Freshly prepared solutions of 1 per cent. dimethyl-p-phenylenediamine and $\mathbf{0 . 3}$ per cent. tetramethyl-p-phenylenediamine were used for direct plate testing of colonies. Tests were also performed by transferring organisms, picked with a platinum loop (tested for inertness), to filter papers moistened separately with 1 per cent. solutions of these reagents. A strong colour in not more than $10 \mathrm{~s}$ was recorded as positive.

Lysine decarboxylase. NCTC micromethod (Shaw and Clarke, 1955).

Nitrate reduction. Method of Cook (1950).

Inoculation of plates. Plates in tests described below were inoculated as for antibioticsensitivity tests, except that an inoculum dilution of $10^{-4}$ was used as well as one of $10^{-2}$.

Starch hydrolysis. Soluble starch (Difco) to final concentration of $0 \cdot 1$ per cent. (w/v) was added to CHA medium. The medium was autoclaved for $15 \mathrm{~min}$. at $115^{\circ} \mathrm{C}$. Cultures were incubated for 3 days, then tested with Lugol's iodine.

Gelatin hydrolysis. Two methods were used: (a) Frazier's (1926) method (see Cowan and Steel, 1965), with 0.4 per cent. gelatin incorporated in CHA plates, and results read at 5 days; $(b)$ Virginia Polytechnic Institute 12 per cent. gelatin stab method (Cato et al., 1969) read at 5 days and at 2 wk.

Casein hydrolysis. Skim milk powder (Difco) was dissolved in distilled water at a 10 per cent. (w/v) concentration, and $250 \mathrm{ml}$ of this solution was added to $250 \mathrm{ml}$ of separately autoclaved and cooled double-strength CHA medium. Results were read at 5 days.

Aesculin hydrolysis. Medium as described by Dowell and Hawkins; results read at 3 and at 5 days.

Malonate utilisation and phenylalanine-deaminase activity. Malonate-phenylalanine medium (Shaw and Clarke), with added haemin ( $25 \mu \mathrm{g}$ per $\mathrm{ml})$, read at 5 days.

Citrate utilisation. Simmons' citrate agar with added haemin $(25 \mu \mathrm{g}$ per $\mathrm{ml})$, examined daily for 7 days.

Urease. Elek's method (Cruickshank, Duguid and Swain, 1968).

Hydrogen sulphide production. Lead acetate papers were kept throughout incubation in the lids of cultures on CHA medium and blood agar.

Sodium azide, potassium cyanide, and bile: added to $\mathrm{CHA}$ in concentrations stated later.

DNA-base composition. The $\mathrm{G}+\mathrm{C}$ content was estimated as described by Hill (1968); a modified Beckman DBG spectrophotometer and a Beckman Tm analyser were used.

Agglutination reactions. Antisera were prepared by immunisation of rabbits tested to establish absence of natural agglutinins. Organisms from $\mathrm{CHA}$ medium were suspended in saline and the density was adjusted to Brown no. 5 standard and then heated at $60^{\circ} \mathrm{C}$ for $30 \mathrm{~min}$. The rabbits were given a first intramuscular dose of $0.1 \mathrm{ml}$., followed after 2 days by $0.25 \mathrm{ml}$, and four subsequent injections at 2-day intervals, increasing by $0.25 \mathrm{ml}$ per dose. Three days after the end of this series the course was repeated with unheated suspensions. Three intravenous injections $(0.1,0.25,0.5 \mathrm{ml})$ of living organisms were then given at 2-day intervals. Animals were bled 2 wk after the last injection.

Stable suspensions of organisms for agglutination were prepared from $\mathrm{CHA}$ cultures and adjusted to an absorbance of 0.3 at $600 \mathrm{~nm}$. They were centrifuged briefly to sediment bacterial aggregates. For each test, $0.5 \mathrm{ml}$ serum dilution and $0.5 \mathrm{ml}$ suspension were 
mixed in a tube, which was examined after incubation at $56^{\circ} \mathrm{C}$ for $2 \mathrm{hr}$ and after further incubation at $37^{\circ} \mathrm{C}$ overnight.

Immunodiffusion studies. These were carried out by the method of Halbert, Swick and Sonn (1955). As antigens, the organisms were used whole and after ultrasonic disruption.

\section{RESULTS}

\section{Facultatively anaerobic organisms}

Colonial morphology. After incubation for $24 \mathrm{hr}$ on blood agar or CHA medium, colonies were $0 \cdot 2-0.5 \mathrm{~mm}$ in diameter, greyish and translucent, and appeared to be within shallow depressions in the agar. Slight increase in colony size was noted on continued incubation and some colonies developed a thin extending edge to give a final diameter up to $3 \mathrm{~mm}$. Aerobic and anaerobic cultures had an odour resembling that of Haemophilus and Pasteurella species.

There was some variation in the visibility of the pits and, when obscured by growth, pits could often be revealed by gently scraping off colonies with a glass rod. The pit and colony were generally circular in outline, but sometimes irregular. We agree with Khairat that it may be difficult to demonstrate in a convincing manner that true pitting has occurred. Oblique lighting of the plate, observation from different angles, and determination of shadow patterns assisted interpretation. An appearance of pitting may be caused by optical effects of the edge of a colony. With marked pitting, observation of a cut block of medium did not show detectable projection of the colony above the surface when the block was held at eye level. When colonies or photographs were observed, reversal of the image sometimes occurred, so that what looked like a depression at one moment seemed to be a projection at another. The same effect with crater photographs is well known to aerial and lunar photographers. Non-pitting variants could be selected from pitting colonies; strain no. A/124/68 was non-pitting on primary isolation.

Microscopic morphology. The organisms were Gram-negative bacilli $0.5 \mu \mathrm{m}$ wide and $1-3 \mu \mathrm{m}$ in length. The morphology was usually regular, but a few short filaments up to $12 \mu \mathrm{m}$ were seen.

Motility was not observed, and electron micrographs of no. NCTC10596 and of four other strains did not show flagella. An occasional process, possibly a pilus, was seen. The surfaces of the strains examined by electron microscopy showed a strikingly convoluted surface (fig. 1), similar to that of Veillonella (Bladen and Mergenhagen, 1964).

Carbon dioxide-enhancement of growth. Aerobic and anaerobic growth of freshly isolated strains was improved by 5-10 per cent. $\mathrm{CO}_{2}$. Three strains, subcultured weekly for several months in a $\mathrm{CO}_{2}$-enriched atmosphere and transferred to plates incubated in humidified air, gave poorer growth than was obtained in air +10 per cent. $\mathrm{CO}_{2}$.

Growth in liquid media. Some strains grew to maximum absorbance of $0 \cdot 3(600 \mathrm{~nm})$ by $48 \mathrm{hr}$ (no further increase), but others grew less well. The addition of 0.2 per cent. agar improved growth.

Optimum temperature. Growth was best at $37^{\circ} \mathrm{C}$, but was good at $40^{\circ} \mathrm{C}$. 
There was poor growth at $42^{\circ} \mathrm{C}$, and none at $44^{\circ} \mathrm{C}$. At $25^{\circ} \mathrm{C}$ visible colonies developed in 7 days.

The optimum $\mathrm{pH}$ was $7 \cdot 3$.

Oxidase reaction. Facultative strains, grown aerobically or anaerobically, with or without added $\mathrm{CO}_{2}$, were strongly oxidase positive, tested with either dimethyl-p-phenylenediamine or the tetramethyl reagent.

Catalase, urease, and indole production. All strains negative.

Lysine decarboxylase. Sixteen strains tested: all positive.

Tests for acid production from 15 substrates (see table II). All strains negative in aerobic and anaerobic cultures.

Nitrate reduction. Nitrate was reduced to nitrite by all strains. Addition of $0 \cdot 1$ per cent. nitrate to $\mathrm{CHA}$ medium enhanced growth under anaerobic conditions.

Miscellaneous reactions. Tests for $\mathrm{H}_{2} \mathrm{~S}$ production were negative or weakly positive. There was no growth on citrate or malonate-phenylalanine medium. Starch, gelatin, casein, and aesculin were not hydrolysed. There was no growth on MacConkey medium, or on CHA medium containing 5 or 10 per cent. bile. Anaerobically, growth occurred on $\mathrm{CHA}+10$ per cent. bile (three strains tested including NCTC10596). Striking resistance to 10 per cent. and 20 per cent. bile was found when the organisms were grown on CHA medium with 0.1 per cent. $\mathrm{KNO}_{3}$ in an atmosphere of 1 per cent. oxygen, 8 per cent. $\mathrm{CO}_{2}, 5$ per cent. $\mathrm{H}_{2}$ and 86 per cent. $\mathrm{N}_{2}$ (no catalyst in jar).

Inhibition by azide and cyanide. The facultative organisms were inhibited under aerobic and anaerobic conditions by 0.02 per cent. azide in CHA medium. Aerobically $0 \cdot 1$ per cent. $\mathrm{KCN}$ was inhibitory, but a trace of growth sometimes occurred anaerobically with this inhibitor.

Haemin and growth. The apparent requirement for haemin for aerobic growth from small inocula was first noticed after application of commercial Flu-strips to cultures on nutrient agar. The requirement was then investigated quantitatively with three strains, including NCTC10596. Inocula harvested from blood agar plates were washed three times with $0.001 \mathrm{M}$ phosphate in 0.85 per cent. saline at $p H 7 \cdot 0$, and suspensions were adjusted to give about 30 and 300 colony-forming units in volumes of $0.025 \mathrm{ml}$. Plates of nutrient agar and cystine-nutrient agar were prepared with added haemin at concentrations $0 \cdot 0,0 \cdot 01,0 \cdot 1,10,25$, and $50 \mu \mathrm{g}$ per $\mathrm{ml}$. Inocula $(0 \cdot 025 \mathrm{ml})$ were dropped on the surface of plates from calibrated Pasteur pipettes. Growth occurred sometimes on the $5 \mu \mathrm{g}$ per $\mathrm{ml}$ medium and regularly on the $10 \mu \mathrm{g}$ per $\mathrm{ml}$ medium, but the colonies were slightly larger on $25 \mu \mathrm{g}$ and $50 \mu \mathrm{g}$ per ml plates at 24 and $48 \mathrm{hr}$. A strain that had been subcultured weekly for a year had a lower haemin requirement, and a non-haemin-requiring variant was selected. The addition of 0.005 per cent. cystine raised the minimum haemin requirement to $20-25 \mu \mathrm{g}$ per $\mathrm{ml}$, but colony size was greater. Cystine at 0.1 per cent. or 0.5 per cent. was strongly inhibitory to growth of the organisms with all haemin concentrations that supported growth in the absence of added cystine. Putrescine (100 $\mu \mathrm{g}$ per $\mathrm{ml})$, menadione $(2.5 \mu \mathrm{g}$ per $\mathrm{ml})$, and ferric chloride, ferrous sulphate, and ethylene-diamine-tetra-acetate (EDTA) in molarities 
comparable to the haemin did not replace haemin. The best growth was obtained on medium enriched with haemin, menadione, and cystine. $H$. influenzae grew on cystine-nutrient agar with haemin $0 \cdot 1 \mu \mathrm{g}$ per $\mathrm{ml}$ and gave slightly larger colonies with haemin $1.0 \mu \mathrm{g}$ per $\mathrm{ml}$. Four different samples of haemin gave similar results in all tests. Organisms grown on all media remained catalase negative.

$D N A$-base composition. The $\mathrm{G}+\mathrm{C}$ content of the organisms was $57-58$ per cent. (seven strains examined). This is the same as the value obtained by Hill, Snell and Lapage (1970). $H$. aphrophilus gave a value of $42-43$ per cent. and $H$. influenzae 38 per cent.

Agglutination reactions and immunodiffusion studies. Sera were prepared against five strains. All sera agglutinated 17 strains tested to titres of 160 or higher, and most to between 320 and 1280. Evidence was obtained of variation in proportions of different antigens present on the organisms, as some strains were agglutinated to lower titre than the strain used to produce the antiserum. Agglutinates were floccular and maximal in less than $2 \mathrm{hr}$ at $56^{\circ} \mathrm{C}$.

Antigenic variety was also indicated by immunodiffusion tests. Up to four shared antigens were detected between pairs of organisms, but with some strains absence of one or two precipitin lines was noted.

Haemophilus species were agglutinated, if at all, to low titre (20 or less). There was no antigenic relationship detectable in either agglutination or immunodiffusion tests between the facultative corroding bacilli and the Bacteroides species (fragilis and oralis), the Vibrio species, or in immunodiffusion tests with the Haemophilus species. A stock suspension of Brucella abortus was not agglutinated. A non-pitting strain, no. 53W, derived from a pitting strain, no. 53P, resembled the parent in all other features except for a slight difference in agglutination titre in antiserum against no. 53P. The non-pitting strain no. A/124/68 was otherwise typical, and had the same $\mathrm{G}+\mathrm{C}$ content as the pitters.

Antibiotic sensitivity. Plates of CHA medium were prepared containing antibiotics in concentrations $20,10,5,1,0.1$, and $0.5 \mu \mathrm{g}$ per ml, except for penicillin $\mathrm{G}$, which was adjusted to give the same range in units per $\mathrm{ml}$. The results are summarised in table $I$.

\section{Anaerobic corroding bacilli}

The four strains no. EDMH1, UAH1, UAH2, and B912 were isolated in anaerobic culture, and did not grow aerobically. They were tolerant of 1 per cent. but not of 5 per cent. oxygen. Of these strains, the first three often grew as agar-pitting colonies, but pitting was minimal or absent with no. B912.

The anaerobes were oxidase-positive, catalase-negative, indole-negative, nitrate-reducing, aesculin-negative, and non-fermentative, so that superficially there were many similarities to the facultative strains.

The oxidase reaction was weaker than with the facultative strains, being 
TAXONOMY OF CORRODING BACILLI

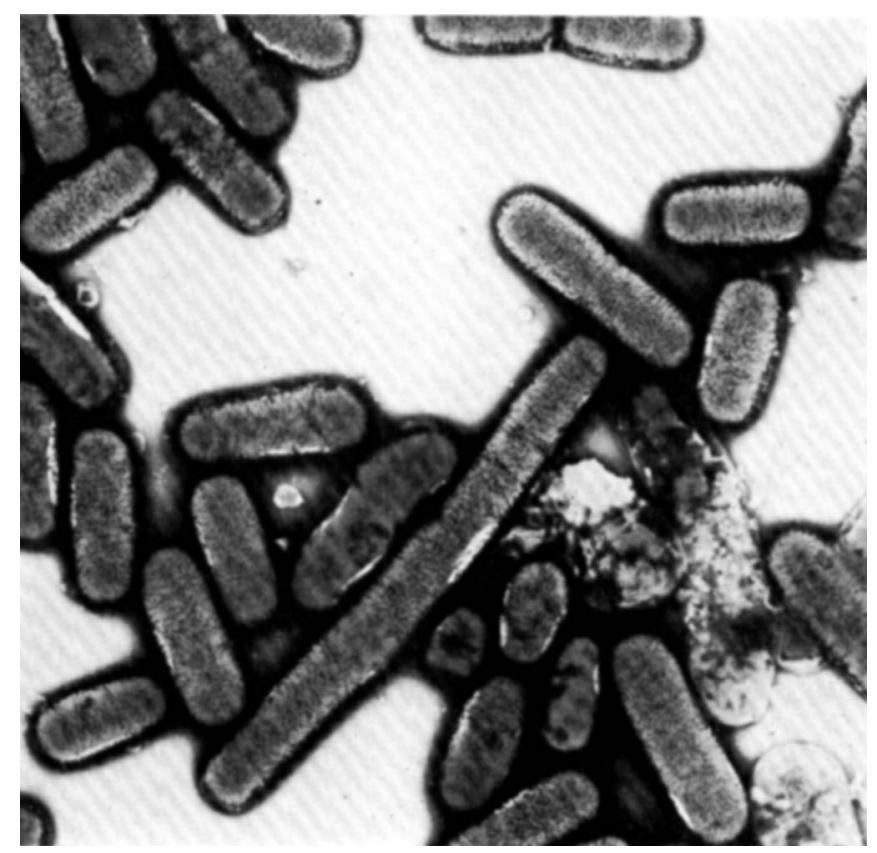

FIG. 1.-Electron micrograph of strain no. NCTC10596, showing "cerebral" appearance of cell wall. Negatively stained with phosphotungstate. $\times 11,400$.

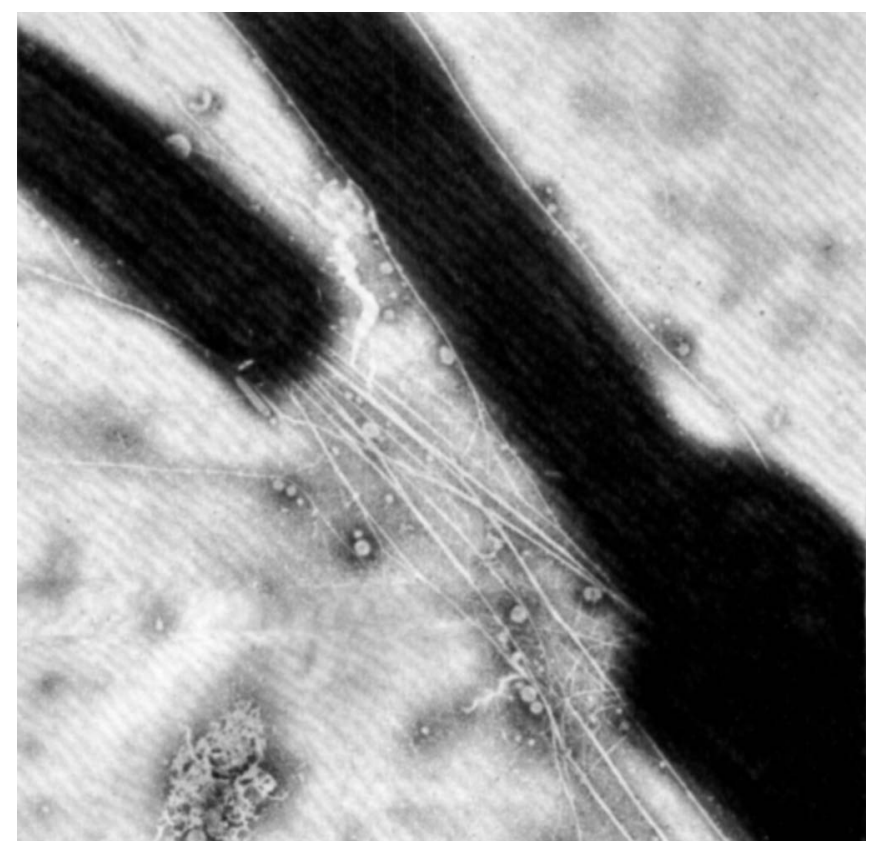

FIG. 2.-Electron micrograph of strain no. UAH2, showing polar processes, negatively stained with phosphotungstate. $\times 16,200$. 
positive with the tetramethyl reagent but weakly positive or doubtful with the dimethyl reagent.

More detailed study revealed important differences between the facultative and anaerobic strains.

Colonial morphology. Colonies of no. B912 showed at most a just detectable tendency to pit the agar and were, in general characteristics, similar to those of a non-pitting variant of a facultative strain, except that they were less translucent, and colonies were often barely visible at $24 \mathrm{hr}$. By $48 \mathrm{hr}$, colonies of

TABLE I

Antibiotic sensitivities of 36 strains of facultative corroding bacilli

\begin{tabular}{|c|c|c|c|c|c|c|}
\hline \multirow{2}{*}{ Antibiotic } & \multicolumn{6}{|c|}{$\begin{array}{l}\text { Number* of strains inhibited by antibiotic concentration } \\
(\mu \mathrm{g} \text { per ml) of }\end{array}$} \\
\hline & $>20$ & 20 & 10 & 5 & 1.0 & $0 \cdot 1$ \\
\hline $\begin{array}{l}\text { Tetracycline } \\
\text { Chloramphenicol } \\
\text { Streptomycin sulphate } \\
\text { Kanamycin } \\
\text { Ampicillin } \\
\text { Cephaloridine } \\
\text { Lincomycin } \\
\text { Erythromycin } \\
\text { Penicillin G } \uparrow\end{array}$ & $\begin{array}{c}1 \\
\ldots \\
6 \\
8 \\
\dddot{2} \\
36 \\
\cdots \\
\cdots\end{array}$ & $\begin{array}{r}0 \\
\dddot{24} \\
26 \\
\dddot{14} \\
0 \\
14 \\
2\end{array}$ & $\begin{array}{r}0 \\
\dddot{6} \\
2 \\
\dddot{20} \\
0 \\
10 \\
4\end{array}$ & $\begin{array}{r}16 \\
3 \\
0 \\
0 \\
12 \\
0 \\
0 \\
12 \\
29\end{array}$ & $\begin{array}{r}19 \\
33 \\
0 \\
0 \\
24 \\
0 \\
0 \\
0 \\
1\end{array}$ & $\begin{array}{l}0 \\
0 \\
0 \\
0 \\
0 \\
0 \\
0 \\
0 \\
0\end{array}$ \\
\hline
\end{tabular}

* Each figure indicates the number of strains inhibited at the corresponding antibiotic concentration, not including strains inhibited by lower concentrations.

$\dagger$ Penicillin $\mathbf{G}$ concentrations in units per $\mathrm{ml}$.

no. B912 were $0.5 \mathrm{~mm}$ in diameter, and slight increase in size was observed at $72 \mathrm{hr}$.

At the time of primary isolation, colonies of no. EDMH1, UAH1, and UAH2 showed well-marked pitting at the periphery. They were minute at $24 \mathrm{hr}$ and increased to $0.5-1 \mathrm{~mm}$ at $48-72 \mathrm{hr}$. After several subcultures, colonies with thin and spreading edges were seen among the compact type. The tendency to form spreading colonies was most marked on the gelatinagar (Frazier-test) medium, and the edge extended to $2-4 \mathrm{~mm}$ from the point of inoculation. On some plates, the spreading type of colony appeared to lie in a shallow depression in the agar, and the colonies had a structure suggesting concentric raised rings with thinner depressed growth between. Because of the occurrence of spreading colonies, an intensive search for motile organisms was made, but none was detected. Thin but smaller peripheral extensions were sometimes seen in colonies of the facultative organisms.

Specific antiserum included in the medium, at 1 in 200 dilution, suppressed spreading, and this observation further stimulated efforts to detect motility, but results were negative.

Microscopic morphology. In Gram-stained preparations, the main difference from the facultative strains lay in a greater tendency to filament formation, 
although this was not always evident. In electron micrographs, flagella were not detected in cultures ranging in age from a few hours to 3 days. Flagella were easily seen on the Vibrio species included for comparison.

In electron micrographs (fig. 2) the three pitting anaerobes showed polar tufts of fine processes, possibly pili (Jackson et al., 1970b). Strain no. B912 resembled the facultatives in lack of this feature, though an occasional cell showed a single process. The surfaces of the anaerobes had a convoluted appearance but, except in no. B912, the convolutions were coarser than in aerobically or anaerobically grown facultative organisms.

Cultural features. Growth was enhanced by $\mathrm{CO}_{2}$, and by inclusion of 0.1 per cent. nitrate in CHA medium. Growth in liquid media was poor. Haemin and menadione enhanced growth on plates, but the effect was small. Strain no. UAH2 did not grow on nutrient agar without added cystine.

The anaerobes were resistant to 0.2 per cent. sodium azide and $0 \cdot 1$ per cent. KCN; they gave a moderately positive Frazier test for gelatinase at 5 days, but the conventional gelatin liquefaction tests (e.g., Cato et al.) were negative at 12 days. Hydrogen sulphide was produced in greater quantity than by the facultative organisms, the test being strongly positive at 2 days on blood agar or CHA.

The haemophilus-like odour of the facultative strains was not present.

On 10 per cent. bile medium with and without $0 \cdot 1$ per cent. $\mathrm{KNO}_{3}$ and under anaerobic conditions, or in a mixture of 1 per cent. oxygen, 8 per cent. $\mathrm{CO}_{2}, 5$ per cent. $\mathrm{H}_{2}$, and 86 per cent. $\mathrm{N}_{2}$, no. EDMH1 and UAH2 were inhibited; no. B912 and UAH1 showed a trace of growth at 4 days.

DNA-base composition. All four anaerobes had a $\mathrm{G}+\mathrm{C}$ content of 28 30 per cent. The values were: no. EDMH1 and UAH2, 28.0 per cent.; no. B912, 28.3 per cent.; no. UAH1, $29 \cdot 7$ per cent.

Agglutination and immunodiffusion studies. The anaerobes were not agglutinated by antisera prepared against the facultative organisms, and antisera prepared against the anaerobes did not agglutinate the facultative organisms.

In immunodiffusion tests, no antigens shared between the facultative and anaerobic strains were found. Two antigens common to all anaerobes were detected, but the four organisms did not give identical reactions. Strains no. B912 and UAH1 lacked a major antigenic component that was present in strains no. EDMH1 and UAH2, but contained a component not detectable in no. EDMH1 and UAH2. No differences were detected between no. EDMH1 and no. UAH2 in immunodiffusion or agglutination tests. Agglutination titres of no. EDMH1 and UAH2 in antiserum against no. EDMH1 were 640, and the agglutinate was floccular, and maximal in less than $2 \mathrm{hr}$ at $56^{\circ} \mathrm{C}$.

Strain no. B912 gave a floccular agglutinate to a titre of 640 with homologous antiserum, and in the same antiserum strains no. EDMH1 and UAH1 gave a fine agglutinate, to a titre of 320 , which was not fully developed until incubation had been continued overnight at $37^{\circ} \mathrm{C}$ after the initial $2 \mathrm{hr}$ at $56^{\circ} \mathrm{C}$. Strain no. UAH1 was not agglutinated by antiserum against no. EDMH1.

No precipitin lines were produced when antisera for no. EDMH1 and B912 were tested against sonically disintegrated vibrios. The vibrios were not 
TABLE II

Summary of main properties of corroding bacilli

\begin{tabular}{|c|c|c|c|c|c|c|c|c|}
\hline \multirow{3}{*}{ Test } & \multicolumn{8}{|c|}{ Results of indicated tests on } \\
\hline & \multirow{2}{*}{$\begin{array}{c}20 \\
\text { facultatively } \\
\text { anaerobic } \\
\text { strains from } \\
\text { University } \\
\text { of Alberta } \\
\text { Hospital } \\
\end{array}$} & \multicolumn{7}{|c|}{ strictly anaerobic strains } \\
\hline & & $\begin{array}{c}\text { EDMH1 } \\
\text { and } \\
\underset{*}{\mathrm{UAH} 2}\end{array}$ & $\begin{array}{c}\text { UAH1 } \\
*\end{array}$ & $\begin{array}{c}\text { B912 } \\
*\end{array}$ & $\begin{array}{c}B . \\
\text { corrodens } \\
\dagger\end{array}$ & $\begin{array}{c}\text { NCDC } \\
\text { group } \\
\text { F2 } \\
\dagger\end{array}$ & $\begin{array}{c}\text { NCDC } \\
\text { group } \\
\text { F3 } \\
t\end{array}$ & $\begin{array}{c}B . \\
\text { corrodens } \\
\ddagger\end{array}$ \\
\hline Anaerobic growth & + & + & + & + & + & + & + & + \\
\hline Aerobic growth & + & - & - & - & - & - & - & - \\
\hline Catalase & - & - & - & - & $\bar{x}$ & $-{ }^{\mathbf{t r}}$ & - & - \\
\hline $\begin{array}{l}\text { Gas: glucose agar deep } \\
\text { Milk (acid) }\end{array}$ & - & - & - & - & V & $-{ }^{t r}$ & + & - \\
\hline $\begin{array}{l}\text { Milk (acid) } \\
\text { Casein hydrolysis }\end{array}$ & $-\underline{\text { or a }}$ & $\bar{t}$ & $\bar{t}$ & $\bar{t}$ & - or a & - & - & $\cdots$ \\
\hline $\begin{array}{l}\text { Gelatin liquefaction (12 } \\
\text { per cent. gelatin) }\end{array}$ & - & - & - & - & $\dddot{-}$ & $\ddot{-}+$ & $\ddot{-}$ & $\dddot{-}$ \\
\hline $\begin{array}{l}\text { Gelatin hydrolysis } \\
\text { (Frazier) }\end{array}$ & - & + & + & + & $\cdots$ & $\cdots$ & $\cdots$ & $\cdots$ \\
\hline $\mathrm{H}_{2} \mathrm{~S}$ production ( 2 days) & - or \pm & + & + & + & $\cdots$ & $\cdots$ & $\cdots$ & $\cdots$ \\
\hline $\begin{array}{l}\text { Indole } \\
\text { Nitrate reduction }\end{array}$ & $\overline{+}$ & $\bar{t}$ & $\bar{t}$ & $\overline{+}$ & $\bar{t}-$ & $\bar{t}$ & $\overline{-}$ & $\overline{+}$ \\
\hline Urease & - & + & + & + & $\ldots$ & $\ldots$ & $\ldots$ & ... \\
\hline Lysine decarboxylase & + & - & - & - & $\cdots$ & $\cdots$ & $\ldots$ & $\cdots$ \\
\hline $\begin{array}{l}\text { Oxidase (tetramethyl- } \\
\text { PPD) }\end{array}$ & + & + & + & + & $\cdots$ & $\cdots$ & $\cdots$ & $\cdots$ \\
\hline Oxidase (dimethyl-PPD) & + & \pm & \pm & \pm & $\dddot{-}$ & $\dddot{-}$ & $\ddot{-}$ & $\underline{-}$ \\
\hline $\begin{array}{l}\text { Starch (acid) } \\
\text { Starch (hydrolysis) }\end{array}$ & $z$ & $\overline{-}$ & 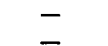 & $\overline{-}$ & $z$ & $\overline{-}$ & $\overline{-}$ & $\bar{z}$ \\
\hline Aesculin (hydrolysis) & $\overline{-}$ & $\overline{-}$ & - & $\overline{-}$ & $\overline{-}$ & - & - & $\overline{-}$ \\
\hline Glucose (acid) & - & - & - & - & - & - & - & $\dddot{-}$ \\
\hline Other fermentations§ & - & - & - & - & - & - & - & - \\
\hline $\begin{array}{l}10 \text { per cent. bile: } \\
\text { anaerobic growth }\end{array}$ & + & - & $\operatorname{tr}$ & $\operatorname{tr}$ & $\cdots$ & ... & $\cdots$ & $\cdots$ \\
\hline $\begin{array}{l}\text { Growth with } 0.02 \text { per } \\
\text { cent. azide ( } 4 \text { days) }\end{array}$ & - & + & + & + & $\cdots$ & $\cdots$ & $\cdots$ & $\cdots$ \\
\hline Motility & - & - & - & - & - & - & - & - \\
\hline $\begin{array}{l}\text { Flagella } \\
\text { Multiple polar processes }\end{array}$ & 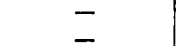 & $\bar{t}$ & $\overline{+}$ & - & - & - & - & - \\
\hline $\begin{array}{l}\text { Multiple polar processes } \\
\text { Agglutination by NCTC }\end{array}$ & $\bar{t}$ & \pm & \pm & $\overline{-}$ & $\cdots$ & $\cdots$ & $\cdots$ & $\cdots$ \\
\hline $\begin{array}{l}\text { Agglutination by NCTC } \\
10596 \text { antiserum }\end{array}$ & & & & & $\cdots$ & $\cdots$ & $\cdots$ & $\cdots$ \\
\hline $\begin{array}{l}\text { Agglutination by EDMH1 } \\
\text { antiserum }\end{array}$ & - & $+\mathrm{C}$ & - & $+F$ & $\cdots$ & $\cdots$ & $\cdots$ & $\cdots$ \\
\hline $\mathrm{G}+\mathrm{C}$ content (per cent.) & $57-58$ & $28 \cdot 0$ & $29 \cdot 7$ & $28 \cdot 3$ & $\cdots$ & $\ldots$ & $\ldots$ & $\cdots$ \\
\hline Flat, spreading colonies & - & $\mathbf{V}$ & V & & $\cdots$ & $\cdots$ & + & $\cdots$ \\
\hline
\end{tabular}

$+=$ Positive $\pm=$ weak positive $;-=$ negative $;. . .=$ not stated.

$\mathbf{C}=$ Coarse $\mathbf{F}=$ fine $; \operatorname{tr}=$ trace; $\mathbf{A}=$ acid $; \mathbf{a}=$ weak acid $\mathbf{V}=$ variable. $\quad P P D=$ paraphenylenediamine.

Superscripts indicate reactions with a minority of strains.

* Results from present study.

$\uparrow$ From Dowell and Hawkins (1968).

$\ddagger$ From Smith and Holdeman (1968).

$\S$ Substrates: adonitol, arabinose, dulcitol, galactose, inositol, lactose, maltose, mannose, mannitol, raffinose, salicin, sorbitol, sucrose, trehalose. 
agglutinated by antisera prepared against the facultative or anaerobic corroding bacilli.

Antibiotic sensitivities. In plate-dilution tests the anaerobes were inhibited by streptomycin, penicillin $\mathrm{G}$, tetracycline, chloramphenicol, kanamycin, and cephaloridine, in concentrations of $0.5 \mu \mathrm{g}$ per ml or less. Oxacillin was inhibitory at the same concentration against all except no. UAH1, which was inhibited at $5.0 \mu \mathrm{g}$ per $\mathrm{ml}$.

\section{Discussion}

Facultatively anaerobic organisms that have been called Bacteroides corrodens form a well-defined group and are often encountered in clinical bacteriology. They are sometimes first detected in anaerobic cultures, perhaps partly because they may be overgrown on aerobic plates by other organisms, but a lower requirement for haemin or some associated factor for anaerobic growth may favour primary anaerobic isolation. The corroding bacilli are occasionally the only micro-organisms detectable in pus subjected to exhaustive bacteriological examination, so that they may perhaps be pathogenic under some circumstances, or be the sole survivors of an initially mixed flora. We have usually found them associated with other bacteria, as for example Streptococcus viridans, Escherichia coli, other facultative anaerobes, Bacteroides species, anaerobic streptococci, Actinomyces israelii (cf. Holm, 1950) and other strict anaerobes. Conditions in material containing mixtures of bacteria may be strongly reducing, so that the organisms might often be growing anaerobically in vivo. Aerobic isolation would be expected when the in-vitro conditions permitted survival during a period of physiological adaptation to an aerobic environment.

The apparent haemin requirement needs further consideration because of the high concentration necessary for growth from small inocula. An impurity might be responsible for this effect, but this seems unlikely. Four batches of haemin purchased on different occasions gave the same results. Haemin may exert a protective effect by binding or inactivating an inhibitor present in the medium or produced during growth (for example, peroxide), and may not be acting simply as a growth factor. Whatever the explanation, the phenomenon has important implications for the design of media for primary aerobic isolation of the organisms from material in which they are present only in small numbers. Ristella pseudoinsolitus is stimulated by haemin, and produces catalase when grown in the presence of haemin (Quinto, Sebald and Prévot, 1963); our organisms grown on medium containing $50 \mu \mathrm{g}$ haemin per $\mathrm{ml}$ were still catalase negative.

Henriksen (1969) found that $\mathrm{CO}_{2}$ did not improve growth of his strains, and Hill et al. (1970) found that $\mathrm{CO}_{2}$ enhancement was not demonstrable after several subcultures in the laboratory. The continued beneficial effect we observed might have arisen from routine maintenance of cultures in a $\mathrm{CO}_{2}$-enriched atmosphere.

The pitting phenomenon, when present, is a striking feature and assists detection of colonies, but the occurrence of non-pitting variants on primary 
isolation and on subculture should be remembered, or the relationship of " non-pitters" to " pitters" may be overlooked.

Strains no. EDMH1, UAH1, and UAH2 were closely similar in general features to the strains described by Khairat (1967). They also had the biochemical characteristics described for $B$. corrodens in the identification schemes of Dowell and Hawkins (1968), and of Smith and Holdeman (1968). Strain no. B912 resembled Khairat's non-pitting strains in colonial morphology. Henriksen pointed out that the negative oxidase reaction given by Khairat's strain might be related to the use of dimethyl-p-phenylenediamine, and our findings support that view. The demonstration of a positive urease reaction indicated a possible difference from Khairat's organisms, but the method used by Khairat was not described in detail and a more strongly buffered test system might have led to a different result. The formation of spreading colonies, referred to by Khairat as "swarming", was a feature of three of our strains, and although motility was strongly suggested we were unable to detect it. It is possible that on certain media the organisms spread by growing in a thin layer, unheaped, rather than by motility, or a slow gliding movement might occur. The existence of minute motile forms is difficult to eliminate, but no small flagellated forms were detected in electron micrographs.

The polar processes, tentatively termed pili, seen in electron micrographs of the anaerobic corroding bacilli no. EDMH1, UAH1 and UAH2 were not found in no. B912, and their presence may be associated with ability to form spreading colonies. Fibrils derived from a surface slime layer might give a similar appearance. Suppression of spreading by antiserum suggests that the surfaces of the bacteria or piliform processes are important for the phenomenon.

The most decisive differences between the facultative and the anaerobic groups are indicated by the agglutination and immunodiffusion patterns and the DNA-base composition. No anaerobic strains have been encountered that are antigenically related to or have the same $\mathrm{G}+\mathrm{C}$ content as the facultative group, but strains that may have been of this kind have been reported (Henriksen).

In an earlier communication (Jackson et al., 1969) we tentatively suggested the name Haemophilus corrodens for the facultative organisms, but their $\mathrm{G}+\mathrm{C}$ content of 58 per cent. is significantly different from that of accepted Haemophilus species that have been investigated. The acceptability of the name would therefore depend on how much weight is attached to the $\mathrm{G}+\mathrm{C}$ content as opposed to phenotypic characteristics in taxonomy. Brucella abortus has a $\mathrm{G}+\mathrm{C}$ content of $55-58$ per cent., but Brucella species are catalasepositive, lysine decarboxylase-negative, and urease-positive. In 23 Pasteurella strains we have examined, the $\mathrm{G}+\mathrm{C}$ content ranged from 41 to 49 per cent.; for $B$. fragilis and $B$. oralis it was 44 per cent., and for $B$. melaninogenicus (B. nigrescens) 41.5 per cent. The value for Moraxella kingii has been reported to be 44.5 per cent. (Henriksen and Bøvre, 1968; Bøvre, Fiandt and Szybalski, 1969) and 49 per cent. (Hill et al.).

The facultative corroding bacilli seem to be an anomaly within the 
Bacteroides genus as at present defined, particularly because of their oxidase positivity and striking aerotolerance, although Loesche (1969) reported that some Bacteroides strains will grow in an atmosphere containing 8 per cent. oxygen, and it is clear that constitution of the medium-e.g., haemin contentmay be important for aerotolerance. On phenotypic grounds, Haemophilus corrodens might still be defended as a better name for the facultative organisms than $B$. corrodens, but because of the somewhat unusual characteristics of these strains we would reinforce Henriksen's suggestion that they might be better assigned to a new genus.

The four anaerobic corroding bacilli could be regarded as Bacteroides species, but they have an unusually low $\mathrm{G}+\mathrm{C}$ content. They differ from the non-fermentative vibrios in antigenic structure and in colonial and microscopic morphology, although Vibrio bubulus has a similar $\mathrm{G}+\mathrm{C}$ content. The identification table of Smith and Holdeman includes $V$. bubulus, $V$. sputorum var. bubulus, $V$. sputorum var. sputorum, and vaginal vibrios, and on the basis of tests included in the scheme, these differ from $B$. corrodens (anaerobic) in being motile and possessing flagella. A non-motile variant of a vibrio might therefore be identified as a non-pitting form of micro-aerophilic $B$. corrodens. The anaerobes exhibit some degree of antigenic heterogeneity although certain antigenic components were common to all four strains. Demonstration of a few of their positive characteristics, particularly urease production, gelatin hydrolysis (Frazier method), and casein hydrolysis would distinguish them from anaerobic biotypes of Eiken's (1958) B. corrodens. They differ from organisms of the National Communicable Diseases Center (NCDC) groups F1 and F3 (Dowell and Hawkins), which are fastidious anaerobes that do not reduce nitrate. Organisms belonging to the NCDC group F3 are described as producing extremely flat, spreading colonies, a point of similarity to three of our strains when growing on certain media. Members of the NCDC group F2 resemble our anaerobes in all biochemical reactions shown in Dowell and Hawkins' table, but tests for oxidase, urease, casein hydrolysis, and the Frazier gelatinase test are not included. On the basis of this table, it would not be possible to distinguish between a nonpitting anaerobic $B$. corrodens and certain strains that would be included in NCDC group F2 (see table II, which summarises the main properties of the organisms examined by ourselves and some other workers).

The absence of definitive differential tests from some published identification schemes has probably led to application of the name $B$. corrodens to organisms that are genotypically widely dissimilar.

\section{SUMMARY}

The name Bacteroides corrodens has been applied to certain Gram-negative facultatively anaerobic organisms that are oxidase-positive, catalase-negative, indole-negative, nitrate-reducing, lysine decarboxylase-positive, non-fermentative, urease-negative, gelatinase-negative, casein hydrolysis-negative, and non-motile. During $2 \mathrm{yr}$, we have encountered no strict anaerobes with similar characteristics, but anaerobic biotypes may exist. The facultative 
strains require haemin for aerobic growth from small inocula, and may appear to be anaerobic if the haemin concentration in the medium is less than $5 \mu \mathrm{g}$ per $\mathrm{ml}$. Variants not requiring haemin occur. Growth is favoured by 0.005 per cent. cystine. The organisms are antigenically related, but strains may vary in the proportions of their different antigens. The $G+C$ content is 57-58 per cent.

Four anaerobic organisms, tolerant of up to 1 per cent. oxygen and having certain superficial similarities to the facultative strains, were investigated. The organisms were oxidase-positive (with tetramethyl- $p$-phenylenediamine), catalase-negative, non-fermentative, urease-positive, gelatinase-positive (Frazier method), and able to hydrolyse casein. The $G+C$ content was $28 \cdot 0-29 \cdot 7$ per cent. In electron micrographs, the spreading strains showed multiple polar processes, but no flagella.

Agar-pitting (corroding) colonies are a striking feature of the facultative and the anaerobic organisms, but both may give non-pitting variants. The taxonomic status of the anaerobes requires further investigation.

The name Bacteroides corrodens has probably been applied by different workers to organisms that are genotypically widely dissimilar.

We wish to thank: Dr S. P. Lapage, Mr L. R. Hill, and Miss J. Midgeley, National Collection of Type Cultures, London, for much useful advice; Dr T. Yamamoto, of the Department of Microbiology, and Dr T. Shnitka, Department of Pathology, University of Alberta, Canada, for assistance with photography and advice on electron microscopy; Miss H. Porten and Miss C. Baker for technical assistance with investigation of haemin requirements and antibiotic sensitivity tests, and Miss D. E. Rhodes for assistance with determination of the DNA-base composition.

\section{REFERENCES}

Bladen, H. A., AND Mergenhagen, S. E. 1964. Ultrastructure of Veillonella and morphological correlation of an outer membrane with particles associated with endotoxic activity. J. Bact., 88, 1482.

BøVre, K., Frandt, M., ANd Szybalski, W. 1969. DNA base composition of Neisseria, Moraxella, and Acinetobacter, as determined by measurement of buoyant density in CsC1 gradients. Canad. J. Microbiol., 15, 335.

Cato, E. D., Cummins, C. S., Holdeman, Lillian V., Johnson, J. L., Moore, W. E. C., Smibert, R. M., AND SMITH, L. DS. 1969. Outline of clinical methods in anerobic bacteriology, Blacksburg.

Cook, G. T. 1950. A plate test for nitrate reduction. J. Clin. Path., 3, 359.

CowAN, S. T., AND Steel, K. J. 1965. Manual for the identification of medical bacteria, Cambridge.

Cruickshank, R., Duguid, J. P., and Swain, R. H. A. 1968. Medical microbiology, 11th ed., Edinburgh, p. 829.

Dowell, V. R., AND HAWKINS, T. M. 1968. Laboratory methods in anaerobic bacteriology: NCDC laboratory manual. U.S. Publ. Hlth Serv. Publn no. 1803.

EIKEN, M. 1958. Studies on an anaerobic, rod-shaped, Gram-negative microorganism: Bacteroides corrodens $\mathrm{N}$ sp. Acta path. microbiol. scand., 43, 404.

Halbert, S. P., Swick, Lois, AND SonN, Constance 1955. The use of precipitin analysis in agar for the study of human streptococcal infections. II. Ouchterlony and Oakley technics. J. Exp. Med., 101, 557.

HeNRIKSEN, S. D. 1969. Corroding bacteria from the respiratory tract. 2 Bacteroides corrodens. Acta path. microbiol. scand., 75, 91. 
Henriksen, S. D. AND Bøvre, K. 1968. Moraxella kingii sp. nov., a haemolytic, saccharolytic species of the genus Moraxella. J. Gen. Microbiol., 51, 377.

HILL, L. R. 1968. In Identification methods for microbiologists, pt B, ed. by B. M. Gibbs and D. A. Shapton, New York, p. 177.

Hill, L. R., SNell, J. J. S., AND LapaGe, S. P. 1970 . Identification and characterisation of Bacteroides corrodens. J. Med. Microbiol., 3, 483.

Holm, P. 1950. Studies on the aetiology of human actinomycosis. 1. The "other microbes" of actinomycosis and their importance. Acta path. microbiol. scand., 27, 736.

JACkson, F. L., Goodman, YvonNe E., AND Wong, PUI C. 1969. Investigation of the status of certain Haemophilus-like organisms hitherto classified as Bacteroides corrodens. Bact. Proc., p. 103.

Jackson, F. L., Goodman, Yvonne E., Wong, Pui C., And Whitehouse, R. L. S. 1970a. Facultative and anaerobic organisms which have been called Bacteroides corrodens. Society for General Microbiology Proceedings, p. viii, March.

Jackson, F. L., Goodman, Yvonne E., Wong, PuI C., ANd Whitehouse, R. L. S. $1970 b$. Comparison of certain agar-pitting organisms designated Bacteroides corrodens. Bact. Proc., p. 75.

KHAIRAT, O. 1967. Bacteroides corrodens isolated from bacteriaemias. J. Path. Bact., 94, 29.

LoESCHE, W. J. 1969. Oxygen sensitivity of various anaerobic bacteria. Appl. Microbiol., $18,723$.

Quinto, G. C., Sebald, M., ANd Prévot, A. R. 1963. Études sur le pouvoir pathogène de Ristella pseudoinsolita. Rôle de l'hémine dans sa croissance. Annls Inst. Pasteur, Paris, 105, 455.

REINHOLD, L. 1966. Untersuchungen an Bacteroides corrodens (Eiken, 1958). Zentbl. Bakt. ParasitKde, Abt. I, Orig., 201, 49.

Shaw, Constance, and Clarke, Patricta H. 1955. Biochemical classification of Proteus and Providence cultures. J. Gen. Microbiol., 13, 155.

SMTth, L. DS., AND Holdeman, LILliaN V. 1968. The pathogenic anaerobic bacteria, Springfield, p. 102. 